\title{
Polycarbonate surface modified by argon cluster ion beams
}

$\operatorname{AUTHOR}(S):$

Zemek, J; Yamada, I; Takaoka, G; Matsuo, J

\section{CITATION:}

Zemek, J ...[et al]. Polycarbonate surface modified by argon cluster ion beams. JOURNAL OF VACUUM SCIENCE \& TECHNOLOGY B 1999, 17(6): 2653-2655

ISSUE DATE:

1999

URL:

http://hdl.handle.net/2433/50109

RIGHT:

Copyright 1999 American Vacuum Society 


\title{
Polycarbonate surface modified by argon cluster ion beams
}

\author{
J. Zemek ${ }^{\mathrm{a})}$ \\ Institute of Physics, Academy of Sciences, 16253 Prague 6, Czech Republic \\ I. Yamada, G. Takaoka, and J. Matsuo \\ Ion Beam Engineering Experimental Laboratory, Kyoto University, Kyoto 606-01, Japan
}

(Received 27 May 1999; accepted 20 August 1999)

\begin{abstract}
X-ray induced photoelectron spectroscopy and atomic force microscopy were used to gain detailed information on surface topography, composition and bonding among atoms in a near-surface region of untreated and modified polycarbonate surfaces by argon cluster and argon monomer ion irradiation. As a consequence of the cluster ion beam impingement on the polycarbonates, their surfaces become rough with polymer structure partially damaged. Surprisingly, the surface irradiated by argon monomer ions was found less rough but the polymer structure in a surface region completely lost its integrity and an amorphous (hydrogenated) carbon layer was formed. (C) 1999 American Vacuum Society. [S0734-211X(99)02006-5]
\end{abstract}

Recently, a novel method of modification of solid surfaces has been developed and successfully used for study of cluster ion interactions with several inorganic solid targets. $^{1-4}$ Using Ar cluster ions, the sputtering yield was measured to be 10-1000 times higher, smoothing of metal and semiconductor surfaces was observed at the normal impact and an angular distribution of sputtered species deviated substantially from a cosine law $^{1-4}$ predicted for a monomer ion sputtering. ${ }^{5}$ Results have indicated that the cluster irradiation process is quite different from that of monomer ions.

The bisphenol-A-polycarbonate $\left[-\mathrm{C}_{6} \mathrm{H}_{4}-\mathrm{C}\left(\mathrm{CH}_{3}\right)_{2}-\mathrm{C}_{6}\right.$ $\left.\mathrm{H}_{4}-\mathrm{O}-\mathrm{CO}-\mathrm{O}-\right]_{n}$, denoted as PC, supplied by Mitsubishi Engineering Plastics Co., was used as $25 \times 25 \times 2 \mathrm{~mm}^{3}$ samples. A reference PC surface was prepared by cutting a $\mathrm{PC}$ just before analysis. The ion irradiated surfaces were exposed to air before their analysis until stated otherwise.

Neutral argon clusters were generated by adiabatic expansion of compressed Ar gas through a narrow nozzle. Following ionization by electron bombardment, the cluster ion beam was focused, mass separated, accelerated to $20 \mathrm{keV}$ and scanned to irradiated the PC uniformly. The mean cluster size reached 3000 atoms. A detailed description of the technique used can be found elsewhere. ${ }^{1}$

Photoelectron spectra were recorded by an ADES-400 (V.G. Scientific) electron spectrometer with $\mathrm{Mg} K \alpha$ radiation $(1254 \mathrm{eV})$. The spectrometer was calibrated by the $\mathrm{Au}$ $4 f 7 / 2$ line peaked at $84.0 \mathrm{eV}$ [full width at half maximum (FWHM) of 1.0 at $20 \mathrm{eV}$ pass energy]. Photoelectron spectra were charge corrected with respect to the lowest binding energy component of the $\mathrm{C} 1 \mathrm{~s}$ line peaked at $284.5 \mathrm{eV}$. All samples were analyzed in as-received state, no sputter cleaning was used.

$\mathrm{C}$ and $\mathrm{O}$ atomic concentrations, summarized in Table I, were determined semiquantitatively within a model of a solid homogeneous in composition. Peak areas were corrected for photoelectron cross sections, asymmetry parameters, inelastic mean free paths and measured transmission function of

${ }^{\text {a)} E l e c t r o n i c ~ m a i l: ~ z e m e k @ f z u . c z ~}$ the electron energy analyzer. Close agreement between the $\mathrm{O} / \mathrm{C}$ ratio measured for the reference sample and the theoretical value indicates that the reference PC surface is representative of the PC. ${ }^{6}$ The untreated PC surface exposed to air for an extended period of time possesses a higher oxygen content. Ar cluster ion irradiated PC surfaces exposed to air appear to be oxygen rich noticeably with respect to the reference PC. The sample surface modified by a dose of 1 $\times 10^{14}$ ions $/ \mathrm{cm}^{2}$ possessed the highest oxygen inclusion. Its $\mathrm{O} / \mathrm{C}$ ratio reached $178 \%$ of the theoretical value. This correlates well with a degree of a surface roughness examined by atomic force microscopy (AFM). The in situ Ar monomer ion irradiated PC surface $\left(10 \mathrm{keV}, 1 \times 10^{15}\right.$ ions $/ \mathrm{cm}^{2}$, at normal incidence) consisted of $\mathrm{C}$ atoms only [and some $\mathrm{H}$ not seen by x-ray photoelectron spectroscopy (XPS)], no oxygen signal was observed.

High resolution $\mathrm{C} 1 s$ and $\mathrm{O} 1 s$ spectra of the untreated and Ar ion cluster irradiated PC surfaces are shown in Figs. 1 and 2 . In agreement with the literature, ${ }^{6-8}$ the $\mathrm{C} 1 s$ peak of the reference sample has been resolved by four Gaussian components corresponding to the aromatic $\mathrm{C}(284.5 \mathrm{eV})$, the aliphatic $\mathrm{C}(285.0 \mathrm{eV})$, the $\mathrm{C}-\mathrm{O}$ functional group $(286.2 \mathrm{eV})$ and the $\mathrm{C}=\mathrm{O}$ carbonyl function group (290.5 eV). The substantial differences among the $\mathrm{C} 1 s$ spectra of pristine $\mathrm{PC}$ and Ar cluster ion irradiated surfaces are found in a region of

TABLE I. Oxygen and carbon atomic concentrations in at $\%$ at pristine and modified polycarbonate surfaces; $R_{a}$ in $\mathrm{nm}$ is the average surface roughness.

\begin{tabular}{|c|c|c|c|c|c|}
\hline Sample & Modification & $\mathrm{C}$ & $\mathrm{O}$ & $\mathrm{O} / \mathrm{C}$ & $R_{a}$ \\
\hline PC, theoretical & & 84.2 & 15.8 & 0.188 & \\
\hline $\mathrm{PC}$, reference & & 83.8 & 16.2 & 0.194 & \\
\hline $\mathrm{PC}(*)^{\mathrm{a}}$ & & 80.6 & 19.4 & 0.241 & 0.3 \\
\hline $\mathrm{PC}+10^{14} \mathrm{Ar}^{+}$ & clusters $/ \mathrm{cm}^{2}(*)$ & 74.9 & 25.1 & 0.335 & 4.1 \\
\hline $\mathrm{PC}+10^{15} \mathrm{Ar}^{+}$ & clusters $/ \mathrm{cm}^{2}(*)$ & 76.3 & 23.7 & 0.311 & 3.8 \\
\hline $\mathrm{PC}+10^{15} \mathrm{Ar}^{+}$ & monomers $/ \mathrm{cm}^{2}$ & 100.0 & 0 & 0 & \\
\hline $\mathrm{PC}+10^{15} \mathrm{Ar}^{+}$ & monomers $/ \mathrm{cm}^{2}(\#)^{\mathrm{a}}$ & 90.7 & 9.3 & 0.103 & 0.5 \\
\hline
\end{tabular}

The sample surface was exposed to air under laboratory conditions for several weeks $(*)$, for $2 \mathrm{~h}(\#)$. 


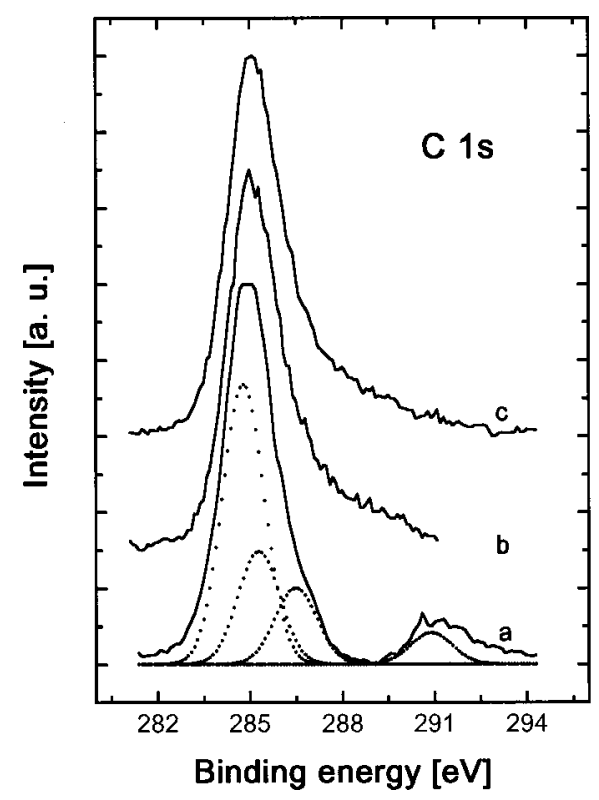

Fig. 1. High resolution C $1 s$ spectra. (a) The reference PC surface with the fit corresponding to the polymer structure (see Ref. 6), (b) the cluster ion irradiated PC surface at $20 \mathrm{keV}$ with a dose of $1 \times 10^{14} \mathrm{ions} / \mathrm{cm}^{2}$, and (c) the cluster ion irradiated PC surface at $20 \mathrm{keV}$ with a dose of 1 $\times 10^{15}$ ions $/ \mathrm{cm}^{2}$.

the $\mathrm{C}=\mathrm{O}$ group. For irradiated surfaces, the intensity in this region is negligible indicating decarbonylation within $8-10$ $\mathrm{nm}$ surface layer (XPS information depth). An increase in the signal intensity observed in between 287 and $289 \mathrm{eV}$ (about $10 \%$ of the overall C $1 s$ intensity) can be ascribed to $\mathrm{C}$ atoms bonded to $-\mathrm{OH}$ species. Curve fitting of the $\mathrm{C} 1 \mathrm{~s}$ spectra of the irradiated PC surfaces revealed a decrease of the aromatic carbon intensity at $284.5 \mathrm{eV}$ by about $50 \%$ and approximately the same increase of both the aliphatic at

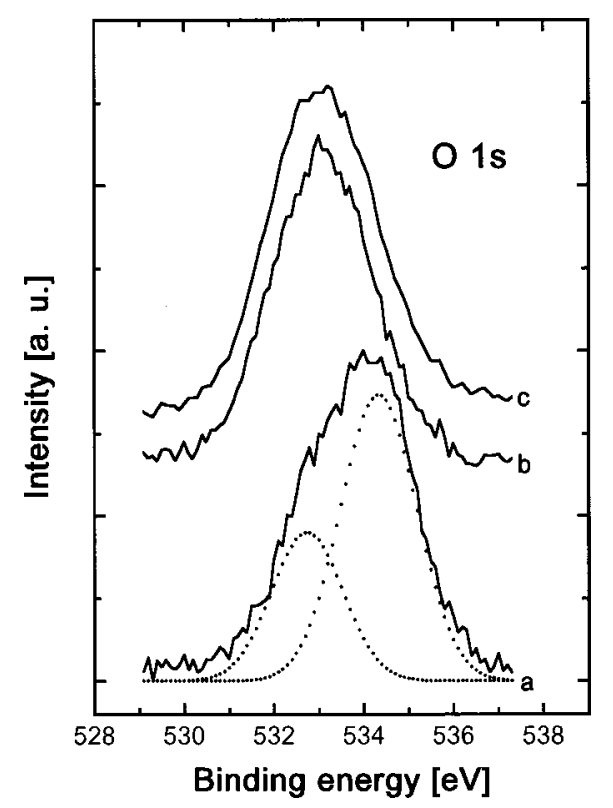

FIG. 2. High resolution O $1 s$ spectra of the same samples as in Fig. 1.
$285.0 \mathrm{eV}$ and the $\mathrm{C}-\mathrm{O}$ functional group spectral intensity at $286.2 \mathrm{eV}$ with respect to the expected values.

The $\mathrm{O} 1 s$ peak of the pristine $\mathrm{PC}$ has been resolved in two components ascribed to oxygen in the $\mathrm{C}=\mathrm{O}(532.4 \mathrm{eV})$ and in the $\mathrm{C}-\mathrm{O}-\mathrm{C}$ functional group $(534.1 \mathrm{eV})$, in the expected 1:2 intensity ratio. ${ }^{6}$ The irradiated sample surfaces show a peak centered at $533 \mathrm{eV}$ with an undetermined number of components, due to the superposition of new species like $(-\mathrm{OH})$ and $-\mathrm{O}-\mathrm{C}$ in a vicinity of $533 \mathrm{eV}$.

Surface topography was observed by atomic force microscopy (SPI-3700, Seiko Instruments). Typical AFM images are displayed in Fig. 3. Due to the normal incidence cluster ion irradiation, a surface roughness increased considerably by about 1 order (see Table I). The highest surface roughness was achieved for a dose of $1 \times 10^{14}$ ions $/ \mathrm{cm}^{2}$. This corresponds to the highest oxygen content which occurred at the same sample surface. The AFM image of $30 \mathrm{keV}$ Ar monomer ion irradiated PC at normal incidence, with a dose of $1 \times 10^{15}$ ions $/ \mathrm{cm}^{2}$, is shown in Fig. 3(d). The treated surface is smoother compared to the cluster irradiated PC and slightly rougher than the pristine PC. Surfaces of inorganic solids irradiated by cluster ions at normal incidence become smooth. ${ }^{1-4}$ The smoothing effect, simulated by molecular dynamic methods, has been explained by a collective momentum transfer of the cluster atoms during impact resulting in shallower lateral sputtering. ${ }^{2}$ On the contrary, we have observed development of surface roughness as a consequence of Ar cluster ion interaction with PC targets. This behavior may be due to the very fast dissipation of cluster energy in the close proximity of every incident cluster. We expect quick evaporation of soft polymer material (with low thermal conductivity and melting point) from the impact area and its close vicinity. Consequently, huge craters markedly overlapping at higher doses should be formed. The less rough surface observed for Ar monomer ion irradiated PC
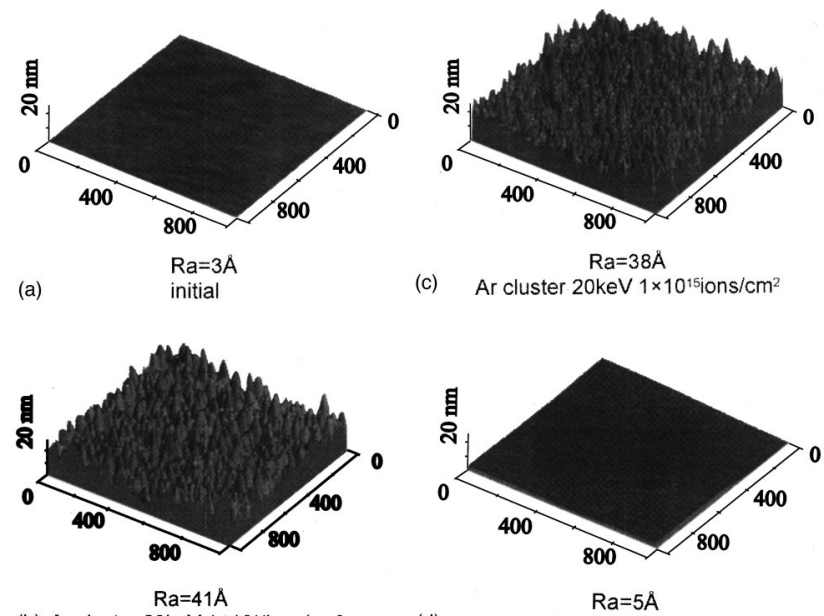

(b) Ar cluster $20 \mathrm{keV} 1 \times 10^{14 i 0 n s} / \mathrm{cm}^{2}$

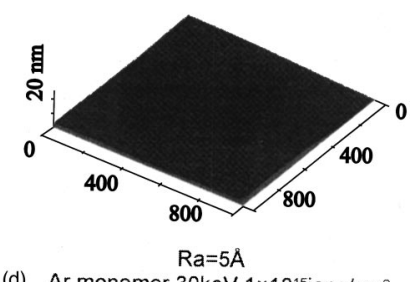

(d) Ar monomer $30 \mathrm{keV} 1 \times 10^{15}$ ions $/ \mathrm{cm}^{2}$

FIG. 3. AFM images $\left(1 \times 1 \mu \mathrm{m}^{2}\right)$ on the pristine PC surface (a), Ar cluster ion irradiated PC surfaces at $1 \times 10^{14}(\mathrm{~b})$ and $1 \times 10^{15} \mathrm{ions} / \mathrm{cm}^{2}$ (c) and $\mathrm{Ar}$ monomer ion irradiated surface at $1 \times 10^{15}$ ions $/ \mathrm{cm}^{2}(\mathrm{~d})$. The average surface roughness $\left(R_{a}\right)$ is given as an average of the modular difference between the height at each point and the average height. 
surfaces at normal incidence could be connected with a complete dissociation and carbonization of a surface layer of the PC target, well documented by XPS results. Recently, similar behavior, namely the surface smoothing and carbonization, has been observed for $\mathrm{N}$ monomer ion beam modified polyimide surface studied by AFM. The irradiation to the fluences below $1 \times 10^{15} \mathrm{~cm}^{-2}$ led to dramatic smoothing of the surface due to ion beam induced sputtering and surface compaction. ${ }^{9}$

In summary, Ar cluster ion irradiation of PC surfaces at the normal incident angle induced the following modification of the polymer surface: almost complete decarbonylation as well as partial fragmentation of aromatic rings occurred in a surface layer of $8-10 \mathrm{~nm}$ and the surface became rough. Ar monomer ion irradiation of PC surfaces led, in contrast to the Ar cluster ion irradiation, to a less rough surface but the polymer structure in the surface region was completely de- stroyed (carbonized) and $a-\mathrm{C}$ or $a-\mathrm{C}(\mathrm{H})$ surface layer was formed.

This work was realized thanks to the Programme KONTAKT 177/1999: Czech-Japan scientific and technical collaboration.

${ }^{1}$ I. Yamada and J. Matsuo, Mater. Res. Soc. Symp. Proc. 427, 265 (1996). ${ }^{2}$ Z. Insepov and I. Yamada, Nucl. Instrum. Methods Phys. Res. B 121, 44 (1997).

${ }^{3}$ J. Matsuo, N. Toyoda, M. Akizuki, and I. Yamada, Nucl. Instrum. Methods Phys. Res. B 121, 459 (1997).

${ }^{4}$ W. K. Chu, Y. P. Li, J. R. Liu, J. Z. Wu, S. C. Tidrow, N. Toyoda, J. Matsuo, and I. Yamada, Appl. Phys. Lett. 72, 246 (1998).

${ }^{5}$ S. Hofmann, Rep. Prog. Phys. 61, 827 (1998).

${ }^{6} \mathrm{G}$. Beamson and D. Briggs, High Resolution XPS of Organic Polymers. The Scienta ESCA 300 Database (Wiley, Chichester, 1992).

${ }^{7}$ M. C. Burrell and M. G. Tilley, J. Vac. Sci. Technol. A 12, 2507 (1994).

${ }^{8}$ J. E. Klemberg-Sapietha, D. Poitras, L. Martinu, N. L. S. Yamasaki, and C. W. Lantman, J. Vac. Sci. Technol. A 15, 985 (1997).

${ }^{9}$ V. Śvorčík, E. Arenholz, V. Rybka, and V. Hnatowicz, Nucl. Instrum. Methods Phys. Res. B 122, 663 (1997). 